\title{
Mild and Efficient Deoxygenation of Epoxides with Bis(cyclopentadienyl)titanium(IV) Dichloride-Indium System
}

\author{
Kwang Hyun Choi, Kyung Il Choi, ${ }^{\dagger}$ Joong Hyup Kim, ${ }^{\dagger}$ Cheol Min Yoon, and Byung Woo Yoo* \\ Department of Advanced Materials Chemistry, Korea University, Jochiwon, Chungnam 339-700, Korea \\ *E-mail: bwyoo@korea.ac.kr \\ ${ }^{\dagger}$ Biochemicals Research Center, Korea Institute of Science and Technology, Cheongryang, Seoul 130-650, Korea \\ Received May 12, 2005
}

Key Words : Epoxides, Deoxygenation, Indium, Titanium

The deoxygenation of epoxides to olefins is an important synthetic transformation in organic chemistry. Since the combination epoxidation/deoxygenation would provide a useful protection/deprotection sequence for the multiple bond, a variety of methods have been devised to accomplish the transformation. ${ }^{1}$ These include $\mathrm{FeCl}_{3} / n$-BuLi, ${ }^{2} \mathrm{NaOH} /$ $n$ - $\mathrm{Bu}_{4} \mathrm{NBr},{ }^{3} \mathrm{Mo}(\mathrm{CO})_{6},{ }^{4} \mathrm{SmI}_{2},{ }^{5} \mathrm{Cp}_{2} \mathrm{TiCl}_{2} / \mathrm{Mg},{ }^{6}$ and dimethyl diazomalonate. ${ }^{7}$ However, many of these remain incompatible with other functional groups in the organic substrates and require expensive reagents and harsh reaction conditions. There still exist a need for the development of new efficient and readily available reagents for this conversion. The chemical reactivity of $\mathrm{Cp}_{2} \mathrm{TiCl}_{2} / \mathrm{M}$ system $(\mathrm{M}=\mathrm{Zn}, \mathrm{Al}$, $\mathrm{Mg}, \mathrm{Sm}$ ) has been the subject of considerable interest and the reducing ability of these systems has been extensively studied. ${ }^{8}$ Because of the close resemblance of indium to magnesium and zinc in several respects, including first ionization potential, we considered that $\mathrm{Cp}_{2} \mathrm{TiCl}_{2} / \mathrm{In}$ system can be an efficient reagent for the deoxygenation of epoxides to olefins. Thus we have investigated the reactions of $\mathrm{Cp}_{2} \mathrm{TiCl}_{2} / \mathrm{In}$ system with various epoxides and found that epoxides can be rapidly deoxygenated to give the corresponding olefins in good to excellent yields (eq. 1). Herein we describe a new and efficient deoxygenation of a variety of epoxides to olefins with $\mathrm{Cp}_{2} \mathrm{TiCl}_{2} / \mathrm{In}$ system in THF under mild conditions. Due to the unique features of high<smiles>[R]C1([R])OC1([R])[R]</smiles>

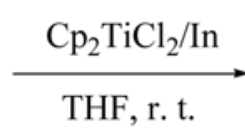

1<smiles>[R]C([R])=C([R3])[R]</smiles>

2 oxophilicity and reducing power, low valent titanium species as reducing reagents for organic molecules and their applications in organic synthesis have been widely explored over the last three decades. ${ }^{9}$ The low-valent titanium(III) complex was readily generated by the in situ reduction of bis(cyclopentadienyl)titanium(IV) dichloride with powdered indium for $30 \mathrm{~min}$ at reflux. The results on the deoxygenation of structurally different epoxides are given in Table 1. In most cases, the overall yields were excellent and the reaction is fast in all cases with substrates reacting completely in less than 10 min at room temperature. Some control experiments revealed that epoxides could not be deoxygenated by $\mathrm{Cp}_{2} \mathrm{TiCl}_{2}$ or indium alone under the present condition and starting materials were recovered unchanged. It was observed that 2:1 ratio of $\mathrm{Cp}_{2} \mathrm{TiCl}_{2}$ and indium was found to be the best ratio in terms of yield and reaction time. ${ }^{10}$ In continuation of our study on low-valent titanium reagents for organic transformations, ${ }^{11}$ we have found that $\mathrm{Cp}_{2} \mathrm{TiCl}_{2}$ /indium system is a convenient and efficient reagent for converting epoxides to olefins. In order to explore the scope and limitations of this reagent system we have tested its applicability for selective deoxygenation of various epoxides bearing other potentially labile functional groups. The functional group tolerance of this method is evident from entries 2-7 which show that carbonyl functions, ether, ester, vinyl, and bromo groups are inert under the conditions described here. Note that particularly high yields resulted if the olefin formed was a conjugated one. The epoxide carrying a carbonyl in the $\alpha$ position $(\alpha, \beta$-epoxy ketones) gave an excellent yield of deoxygenated product which makes possible the use of the oxirane ring as protecting group for conjugated double bonds (entries 2 and 3). To our knowledge very few reagents have been reported for the deoxygenation of $\alpha, \beta$-epoxy ketones into the corresponding $\alpha, \beta$-enones. ${ }^{12}$ Every epoxide carrying a phenyl group in the $\alpha$ position gave an excellent yield of deoxygenated product (entries 6,7 , and 8 ). The reduction accommodates highly substituted and sterically hindered epoxides (entries 4, 8, 10, 11, and 12). In case of (E)-stilbene oxide, only (E)-stilbene was obtained (entry 8 ). The relatively moderate yields of entries 11 and 12 have been attributed to their high volatility. All the compounds obtained showed IR, NMR and mass spectral data compatible with the structure. Thus, we have been able to demonstrate the utility of easily accessible $\mathrm{Cp}_{2} \mathrm{TiCl}_{2} / \mathrm{In}$ system as a convenient reagent for effecting chemoselective deoxygenation of epoxides. Although the role of bis(cyclopentadienyl)titanium(IV) dichloride is not clear at the present stage, it is likely that reduction of titanium(IV) with indium provides low valent titanium species, ${ }^{13}$ which reacts with the epoxides $\mathbf{1}$ to give the corresponding olefins 2 . The notable advantages of this methodology are mild reaction condition, fast reaction time, simple operation, and tolerance of other 
Table 1. Deoxygenation of epoxides with $\mathrm{Cp}_{2} \mathrm{TiCl}_{2} / \mathrm{In}$ system

Entry

${ }^{a}$ All the compounds obtained showed NMR, IR, and mass spectra data compatible with the structure. ${ }^{b}$ Isolated yields.

sensitive functional groups.

In conclusion, we believe that the procedure using $\mathrm{Cp}_{2} \mathrm{TiCl}_{2} / \mathrm{In}$ system described here will present a useful and convenient alternative to the existing methods for deoxygenation of epoxides to olefins. Further investigations of more useful applications are currently in progress.

Acknowledgments. This work was financially supported by a Korea University Grant and we are thankful to Korea
Institute of Science and Technology for providing general facilities for this work.

\section{References}

1. (a) Kraus, G. A.; Thomas, P. J. J. Org. Chem. 1988, 53, 1395. (b) Johnson, W. S.; Plummer, M. S.; Pulla Reddy, S.; Bartlett, W. R. J. Am. Chem. Soc. 1993, 115, 515. (c) Mahesh, M.; Murphy, J. A.; Wessel, H. P. J. Org. Chem. 2005, 70, 4118.

2. Fujisawa, T.; Sugimoto, K.; Ohta, H. Chem. Lett. 1974, 883.

3. Santos, R. B.; Brocksom, T. J.; Brocksom, U. Tetrahedron Lett. 1997, 38, 745 .

4. Patra, A.; Bandyopadhyay, M.; Dipakranjan, M. Tetrahedron Lett. 2003, 44, 2355.

5. Concellon, J. M.; Bardales, E. Org. Lett. 2002, 2, 189.

6. Schobert, R. Angew. Chem. Int. Ed. Engl. 1988, 27, 855.

7. Martin, M. G.; Ganem, B. Tetrahedron Lett. 1984, 25, 251.

8. (a) Coutts, R. S. P.; Wailes, P. C. J. Organomet. Chem. 1973, 47, 375. (b) Nelson, T. R.; Tufariello, J. J. J. Org. Chem. 1975, 40, 3159. (c) Huang, Y.; Liao, P.; Zhang, Y. Synth. Commun. 1997, 27 , 1059.

9. (a) McMurry, J. E. Chem. Rev. 1989, 89, 1513. (b) Lenoir, D. Synthesis 1989, 883. (c) Furstner, A.; Bogdanovic, B. Angew. Chem., Int. Ed. Engl. 1996, 35, 2442. (d) Dushin, R. G. In Comprehensive Organometallic Chemistry II; Hegedus, L. S., Ed.; Pergamon: Oxford, 1995; Vol. 12, p 1071.

10. A typical procedure for the deoxygenation of epoxides is as follows: Indium powder $(115 \mathrm{mg}, 1.0 \mathrm{mmol})$, bis(cyclopentadienyl)titanium(IV) dichloride (500 $\mathrm{mg}, 2.0 \mathrm{mmol})$ and THF $(5 \mathrm{~mL})$ were mixed under nitrogen atmosphere and the resulting mixture was stirred at reflux for $30 \mathrm{~min}$. A dark-red solution of the lowvalent titanium-indium complex was obtained and cooled to room temperature. To this solution, a solution of 2-benzyl-oxirane (67 $\mathrm{mg}, 0.5 \mathrm{mmol})$ in THF (1 mL) was added dropwise. Stirring was continued for $10 \mathrm{~min}$ at room temperature under nitrogen. The reaction mixture was filtered through celite and extracted with ether. The combined organic layer was washed with brine and dried over anhydrous $\mathrm{MgSO}_{4}$. The solvent was removed and residue was purified by column chromatography on silica gel (hexane : ethyl acetate $=20: 1)$ to afford allyl benzene $(64 \mathrm{mg}, 92 \%)$.

11. (a) Yoo, B. W.; Choi, K. H.; Ko, J. J.; Nam, G. S.; Chang, K. Y.; Choi, K. I.; Kim, J. H. Bull. Korean Chem. Soc. 2001, 22, 541. (b) Yoo, B. W.; Choi, K. H.; Lee, S. J.; Yoon, C. M.; Kim, S. H.; Kim, J. H. Synth. Commun. 2002, 32, 63. (c) Yoo, B. W.; Lee, S. J.; Yoo, B. S.; Choi, K. I.; Kim, J. H. Synth Commun. 2002, 32, 2489. (d) Yoo, B. W.; Choi, J. W.; Kim, D. Y.; Hwang, S. K.; Choi, K. I.; Kim, J. H. Bull. Korean Chem. Soc. 2002, 23, 797 .

12. (a) Mandal, A. K.; Mahajan, S. W. Tetrahedron 1988, 44, 2293. (b) Dos Santos, R. B.; Brocksom, T. J.; Brocksom, U. Tetrahedron Lett. 1997, 38, 745. (c) Martin, M. G.; Ganem, B. Tetrahedron Lett. 1984, 25, 251.

13. (a) Gold, H. J. Synlett 1999, 159. (b) Fernandez-Mateos, A.; Martin de la Nava, E.; Pascual Coca, G.; Ramos Silvo, A.; Rubio Gonzales, R. Org. Lett. 1999, 1, 607. (c) McMurry, J. E.; Fleming, M. P. J. Org. Chem. 1975, 40, 2555. (d) McMurry, J. E.; Silvestri, M. G.; Fleming, M. P.; Hoz, T.; Grayston, M. J. Org. Chem. 1978, 43,3249 . 